\title{
A Population-Based Study of Pregnancy and Delivery Characteristics Among Women with Vulvodynia
}

\author{
Ruby H. N. Nguyen • Elizabeth G. Stewart • Bernard L. Harlow
}

To view enhanced content go to www.paintherapy-open.com

Received: June 12, 2012 / Published online: July 21, 2012

(c) The Author(s) 2012. This article is published with open access at Springerlink.com

\section{ABSTRACT}

Introduction: To examine pregnancy and delivery characteristics of women with and without vulvodynia.

Methods: The authors analyzed 227 vulvodynia cases that were less than 45 years old at pain onset; controls were age matched 1:1 to cases and had no history of vulvar pain. Pregnancy and delivery events were assessed after age at

R. H. N. Nguyen $(\bowtie)$ · B. L. Harlow

Division of Epidemiology and Community Health, School of Public Health, University of Minnesota,

1300 S. 2nd Street, Suite 300, Minneapolis, MN 55454, USA

e-mail: nguyen@umn.edu

E. G. Stewart

Department of Obstetrics and Gynecology,

Harvard Medical School, Boston, MA, USA

E. G. Stewart

Vulvovaginal Service, Harvard Vanguard

Medical Associates, Boston, MA, USA

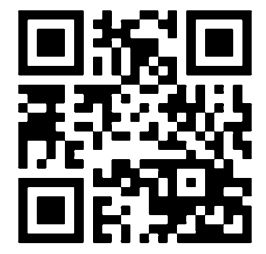

Enhanced content for this article is available on the journal web site:

www.paintherapy-open.com first vulvar pain onset (the reference age) in cases and a matched age in controls.

Results: The authors observed no significant difference between cases and controls in achieving pregnancy after reference age. Also, no difference in pregnancy outcome was observed between cases and controls $(P=0.87)$. There was an indication that cases were more likely to receive a Cesarean section delivery $(P=0.07)$. In addition, $37.1 \%$ of cases who had vaginal delivery versus $11.3 \%$ of controls $(P<0.01)$ reported pain at 2 months postpartum. Comparing only women with vulvodynia, women who had intermittent pain versus constant pain were more than twice as likely to have a pregnancy (adjusted odds ratio 2.26 , 95\% CI 1.10-4.60).

Conclusions: Women with vulvodynia may be as likely as other women to carry their pregnancy to birth; however, they may experience higher rates of Cesarean section delivery and could reflect a selection towards those women with vulvodynia who have inconsistent pain.

Keywords: Cesarean; Fertility; Pain;

Pregnancy; Vaginal delivery; Vulvodynia 


\section{INTRODUCTION}

The symptoms of vulvodynia, such as vulvar pain and burning, have been specifically associated with effects on intercourse frequency. Both decreased libido and reduction in coital frequency have been reported by women with signs and symptoms of vulvodynia $[1,2]$.

When a woman with vulvodynia does become pregnant, it is unclear whether pregnancy or delivery affects the natural history of the condition. One study by Reed et al. [3] reported that, on average, symptoms of vulvodynia did not worsen after a pregnancy, finding that $40 \%$ of women had no change in symptoms, while $30 \%$ of women had a decrease in symptoms. However, this study was based on 17 women with vulvodynia and was restricted to a clinic population. To date, there has been no community-based study of pregnancy and delivery characteristics of women with and without vulvodynia.

It is unclear whether vulvodynia is associated with women's reproduction. In a community-based study in the Boston area, 12,000 women were screened for vulvar pain consistent with vulvodynia [4]. As a part of the study, the authors administered an extensive reproductive health survey. The aim of this analysis is to determine whether vulvar pain symptoms are associated with pregnancy, and to describe pregnancy and delivery characteristics after the onset of vulvodynia pain symptoms.

\section{MATERIALS AND METHODS}

\section{Study Design and Participants}

The Institutional Review Board at both the Brigham and Women's Hospital and the
University of Minnesota approved this study. All women signed informed consent forms before joining the study. In brief, the study collected data between the years 2000 and 2003 from women in the Boston area on history of vulvar pain. Women aged 18-64 years were identified using a sampling of the Massachusetts annual census publication containing names, ages, and addresses (called the Massachusetts Town Books). Weighted sampling was employed to reflect the age and community distributions of all communities based on the US Census data. Using this method, 12,047 women with a confirmed residential listing comprised the target population. Of these women, $67.4 \%(8,125)$ returned a short screening questionnaire that assessed the history of the following four types of vulvar pain symptoms that lasted for three or more months: itching, burning, knife-like sharp pain, pain on contact (with tampon insertion, intercourse, or pelvic examination).

\section{Vulvodynia Case Determination}

Those who reported having symptoms consistent with the International Society for the Study of Vulvovaginal Disease criteria for vulvodynia on their short screening questionnaire were candidates to become a vulvodynia case [5]. These women were screened over the phone for additional vulvodynia-related criteria, including history of vulvar itching, burning, knife-like pain, and pain on contact. Age at onset of symptoms, a brief description of treatments ever used, and intensity were assessed for each pain domain. A specialist in vulvar disease diagnosis (E.G.S.) reviewed all women with vulvar pain symptoms from the self-reported questionnaires and, based on history of pain and other conditions 
that could have explained the vulvar pain, determined the final group of cases. There were 177 women with chronic ( $>3$ months in duration) vulvar pain symptoms, who agreed to participate in the present study. An additional 65 women who were clinically confirmed to have vulvodynia were identified and enrolled from a vulvovaginal specialty clinic (attended by E.G.S.). For each of the 242 cases, a control was matched on age ( \pm 5 years) and area of residence. Previous studies have reported high validity of results when examining populationbased cases and clinically confirmed cases $[4,6]$. Further details regarding the study methods can be found elsewhere $[4,6]$.

To determine events, such as pregnancy occurring after onset of vulvar pain symptoms, the authors developed a reference point in time. Age at first onset of vulvar pain symptoms was determined for each woman with vulvodynia. This age was referred to as the "reference age," and it was assigned to a matched control woman with no vulvar pain history.

\section{Assessing Pregnancy and Delivery Characteristics}

As the authors wanted to determine the fertility among women after first onset of vulvar pain (and reference age in controls), the authors restricted the present study population to women with reference ages less than 45 years. This exclusion criterion eliminated 15 women with vulvodynia and 15 control women, leaving 454 women (227 women with vulvodynia and 227 controls) for the analysis.

A telephone-administered questionnaire assessed each pregnancy history, including dates, pregnancy outcome, mode of delivery, and type of anesthesia. If the delivery was vaginal, women were asked, "Did your episiotomy or tear pain subside by 2 months, or were you in pain for a longer time? ( $\leq 2$ or $>2$ months)." Vulvar pain after delivery was defined as reporting pain for more than 2 months after vaginal delivery.

The authors determined whether the number of pregnancies and other pregnancy-related characteristics after reference age differed by case-control status. For the analysis of number of pregnancies, the authors included only those after the woman's reference age. The first pregnancy after reference age was considered the index pregnancy for the assessment of pregnancy-related characteristics (pregnancy outcome, delivery characteristics, and vulvar pain during the postpartum period). The authors lacked specific data on women's level of pain around conception, during pregnancy, and into the postpartum period.

\section{Statistical Analysis}

All analyses were restricted to pregnancies occurring after the reference age (age at first onset of pain for vulvodynia cases and the matched reference age for controls). The authors hypothesized that women with vulvodynia who had their first onset of pain at a young age may be more prone to problems than those with an older age at pain onset. Therefore, in addition to the overall estimates that use the entire sample of women, findings from a restricted dataset that includes only women with reference ages that were less than 30 years are also presented.

The authors sought to investigate three specific aims: first, determine whether vulvodynia was associated with a reduced likelihood of pregnancy; second, among those who became pregnant, determine if vulvodynia was associated with differences in pregnancy outcomes; and third, among women with vulvodynia only, determine if pain-related 
factors around pregnancy, such as pain that limited intercourse or intermittent (vs. constant) pain, were associated with becoming pregnant.

To address these research aims, the authors conducted three separate analyses. For the first analysis, all 454 women were included (Fig. 1). The authors used univariate conditional logistic regression that accounted for the study's original matching criteria (town of residence and age at interview) to determine factors associated with a reduction in the likelihood of pregnancy after reference age. For the second aim, only women who became pregnant were eligible; therefore, matching was broken. Due to small sample sizes, for this aim the authors present descriptive data and $P$ values using the Chi square test for categorical variables and the Student's $t$ test for the difference in means. Finally, for the third aim, only vulvodynia cases were eligible. The authors used multivariate logistic regression to assess independent characteristics of vulvar pain associated with likelihood of becoming pregnant. Variables that were found to be significant in the univariate analysis were considered $(P \leq 0.05)$, with forward stepwise selection employed (probability of entry set to 0.20 ) for variable selection into the final models. All analyses were performed using STATA/SE ${ }^{\mathrm{TM}}$ v.10 (StataCorp LP, College Station, TX, USA).

\section{RESULTS}

The authors had 227 vulvodynia cases and 227 town- and age-matched controls, all of whom were less than 45 years at first onset of pain (for cases) or whose reference age was less than 45 years (for controls) (Fig. 1). Of those

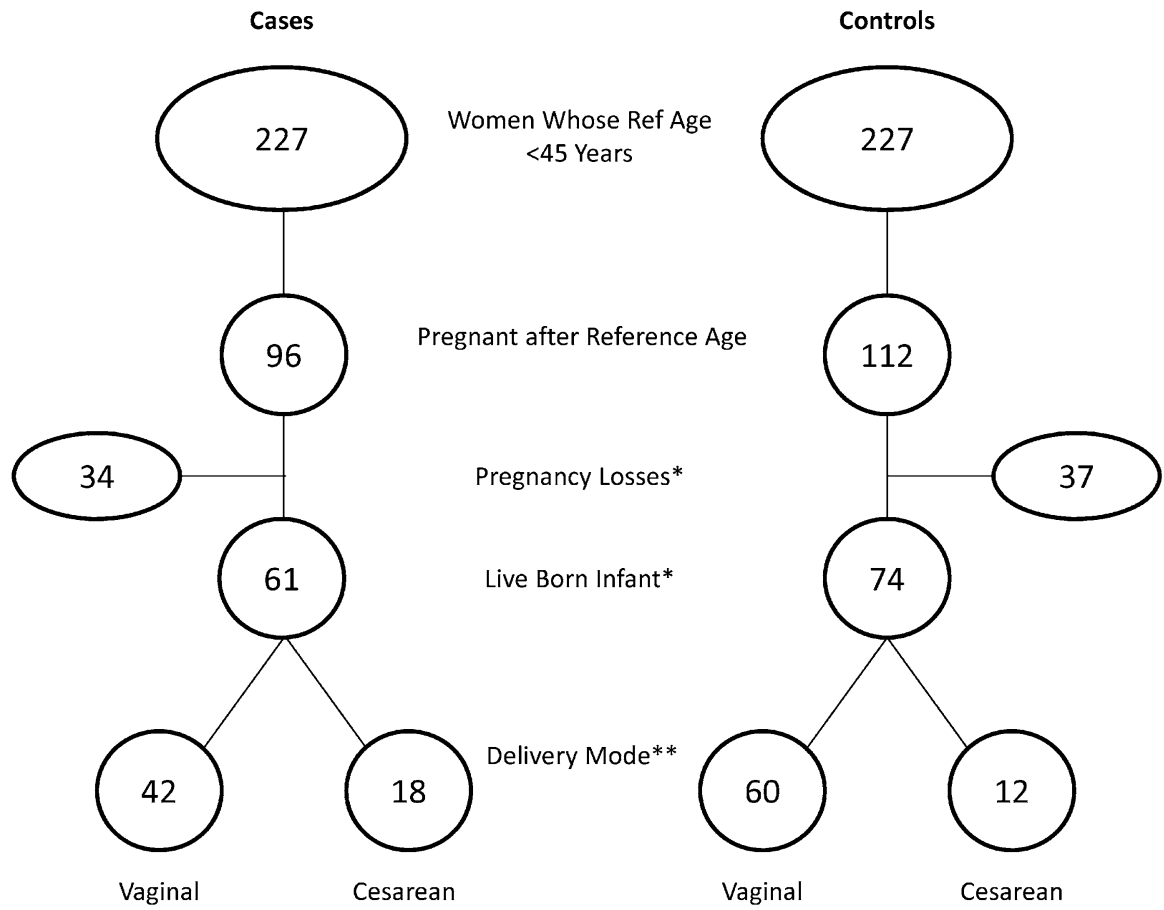

Fig. 1 Flowchart of women in a case-control study of vulvodynia. Outcome of pregnancy and delivery mode were based on the index pregnancy (first pregnancy after reference age). Asterisks one control and one case woman did not report the outcome of the index pregnancy. Double

asterisk two controls and one case did not report the mode of delivery of the index pregnancy. Delivery of nonviable pregnancies, such as miscarriages and stillbirths, were not included 
women, 61 cases and 74 controls went on to have an index pregnancy that resulted in a live born infant. Among cases, 18 (29.5\%) delivered by Cesarean versus 12 (16.2\%) control women.

Table 1 lists the demographic characteristics for all cases and controls $(n=454)$, and for cases and controls with reference ages less than 30 years $(n=356)$. Women with a younger reference age represent $78.4 \%$ of the overall sample.
The present study population was predominantly non-Hispanic white and the majority had a college degree or higher. Among all women, $42.3 \%$ of cases achieved a pregnancy after reference age compared with $49.3 \%$ of controls $(P=0.13)$. The authors also observed a similar finding for women with an earlier reference age $(44.6 \%$ in cases vs. $52.0 \%$ in controls, $P=0.17)$.

Table 1 Demographic characteristics of case women with vulvodynia and controls by age category, Boston, Massachusetts, 2000-2003

\begin{tabular}{|c|c|c|c|c|c|c|}
\hline & \multicolumn{3}{|l|}{ All women } & \multicolumn{3}{|c|}{ Women whose reference age $<30$ years } \\
\hline & $\begin{array}{l}\text { Cases } \\
(n=227)\end{array}$ & $\begin{array}{l}\text { Controls } \\
(n=227)\end{array}$ & $P$ value ${ }^{*}$ & $\begin{array}{l}\text { Cases } \\
(n=177)\end{array}$ & $\begin{array}{l}\text { Controls } \\
(n=179)\end{array}$ & $P$ value \\
\hline Age (years) at interview ${ }^{\mathrm{a}}$ & $35.6(9.5)$ & $35.8(9.6)$ & 0.82 & $33.5(9.1)$ & $34.0(9.3)$ & 0.67 \\
\hline \multicolumn{7}{|l|}{ Race/ethnicity, no. (\%) } \\
\hline Non-Hispanic white & $204(89.9)$ & $192(84.6)$ & 0.06 & $156(88.1)$ & $149(83.2)$ & 0.05 \\
\hline African-American & $6(2.6)$ & $18(7.9)$ & & $6(3.4)$ & $17(9.5)$ & \\
\hline Hispanic & $14(6.2)$ & $9(4.0)$ & & $13(7.3)$ & $9(5.0)$ & \\
\hline Other & $3(1.3)$ & $8(3.5)$ & & $2(1.1)$ & $4(2.2)$ & \\
\hline \multicolumn{7}{|l|}{ Education, no. (\%) } \\
\hline$<$ High school graduate & $4(1.8)$ & $4(1.8)$ & 0.79 & $4(2.3)$ & $3(1.7)$ & 0.68 \\
\hline High school graduate & $15(6.6)$ & $18(7.9)$ & & $10(5.6)$ & $15(8.4)$ & \\
\hline Some college & $35(15.4)$ & $41(18.1)$ & & $31(17.5)$ & $35(19.6)$ & \\
\hline Technical school & $3(1.3)$ & $6(2.6)$ & & $2(1.1)$ & $4(2.2)$ & \\
\hline College graduate & $100(44.1)$ & $89(39.2)$ & & $81(45.8)$ & $69(38.5)$ & \\
\hline Graduate school & $70(30.8)$ & $69(30.4)$ & & $49(27.7)$ & $53(29.6)$ & \\
\hline Ever married, no. (\%) & $167(73.6)$ & $167(73.6)$ & 1.00 & $123(69.5)$ & $124(69.3)$ & 0.96 \\
\hline \multicolumn{7}{|l|}{ Parity at reference age, no. (\%) } \\
\hline 0 & $167(73.6)$ & $162(71.4)$ & 0.82 & $147(83.1)$ & $150(83.8)$ & 0.97 \\
\hline 1 & $30(13.2)$ & $28(12.3)$ & & $19(10.7)$ & $18(10.1)$ & \\
\hline 2 & $17(7.5)$ & $20(8.8)$ & & $6(3.4)$ & $7(3.9)$ & \\
\hline$\geq 3$ & $13(5.7)$ & $17(7.5)$ & & $5(2.8)$ & $4(2.2)$ & \\
\hline Pregnant after reference age, no. (\%) & $96(42.3)$ & $112(49.3)$ & 0.13 & $79(44.6)$ & $93(52.0)$ & 0.17 \\
\hline
\end{tabular}

* $P$ values test between the cases and controls in that sample

a Values are mean (SD) 


\section{Analysis of Achieving Pregnancy After Vulvodynia Onset}

Vulvodynia was not significantly associated with achieving pregnancy when the authors accounted for the study's original matching criteria of town of residence and age at interview (Table 2). When compared with the control women, women with vulvodynia were not significantly less likely to achieve pregnancy after their pain onset (adjusted odds ratio [adj. OR] 0.74, 95\% CI 0.49-1.10); this varied minimally with the younger reference age women. Being non-Hispanic white, highly educated, and never married reduced the odds of pregnancy among these women.

\section{Analysis of Pregnancy Outcome and Pain during the Postpartum Period After Vulvodynia Onset}

Table 3 describes the number of pregnancies and outcomes associated with the first pregnancy after reference age. Among all cases and controls there was no significant difference in the distribution of number of pregnancies after reference age $(P=0.11)$. However, there was an indication of a higher prevalence of nulliparity and having only one pregnancy if a woman develops vulvar pain before the age of 30 years $(P=0.06)$. When the authors excluded nulliparous women, no difference was found in the mean number of pregnancies in the case-control group (among all women, 2.01 vs. $2.18, P=0.35$ ).

The majority of women delivered full-term liveborn infants, and there was no difference in the distribution of pregnancy outcomes between women with and without vulvodynia in all women and the subsample (all women, $P=0.87$ and $<30$ years reference age, $P=0.91$ ). The present data suggest that women with vulvodynia who go on to have a live birth are more likely to have received a Cesarean section (30.0\% vs. $16.7 \%, P=0.07)$.

Vaginal injury during delivery, length of pushing during delivery, and postpartum

Table 2 Characteristics associated with pregnancy using univariate logistic regression models by age category, Boston, Massachusetts, 2000-2003

\begin{tabular}{|c|c|c|c|c|c|c|}
\hline & \multicolumn{6}{|c|}{ Pregnant after reference age for all women } \\
\hline & \multicolumn{3}{|l|}{ All women } & \multicolumn{3}{|c|}{ Women whose reference age $<30$ years } \\
\hline & $\begin{array}{l}\text { No. of women } \\
\text { pregnant after } \\
\text { reference age } \\
(n=208)\end{array}$ & $\begin{array}{l}\text { No. of women } \\
\text { not pregnant } \\
\text { after reference } \\
\text { age }(n=246)\end{array}$ & $\begin{array}{l}\text { Adj. OR } \\
\text { (95\% CI) }\end{array}$ & $\begin{array}{l}\text { No. of women } \\
\text { pregnant after } \\
\text { reference age } \\
(n=172)\end{array}$ & $\begin{array}{l}\text { No. of women } \\
\text { not pregnant } \\
\text { after reference } \\
\text { age }(n=184)\end{array}$ & $\begin{array}{l}\text { Adj. OR } \\
\text { (95\% CI) }\end{array}$ \\
\hline Vulvodynia & 96 & 131 & $0.74(0.49-1.10)$ & 79 & 98 & $0.73(0.46-1.14)$ \\
\hline $\begin{array}{l}\text { Non- } \\
\text { Hispanic } \\
\text { white }\end{array}$ & 176 & 220 & $0.36(0.19-0.66)$ & 144 & 161 & $0.34(0.17-0.66)$ \\
\hline $\begin{array}{l}\text { College } \\
\text { graduate }\end{array}$ & 144 & 184 & $0.64(0.40-1.01)$ & 114 & 138 & $0.46(0.27-0.78)$ \\
\hline Ever married & 189 & 145 & $6.95(3.86-12.5)$ & 154 & 93 & $6.00(3.3-11.0)$ \\
\hline
\end{tabular}

Odds ratios adjusted for the original study matching criteria (age at interview and town or residence)

Adj. $O R$ adjusted odds ratio 


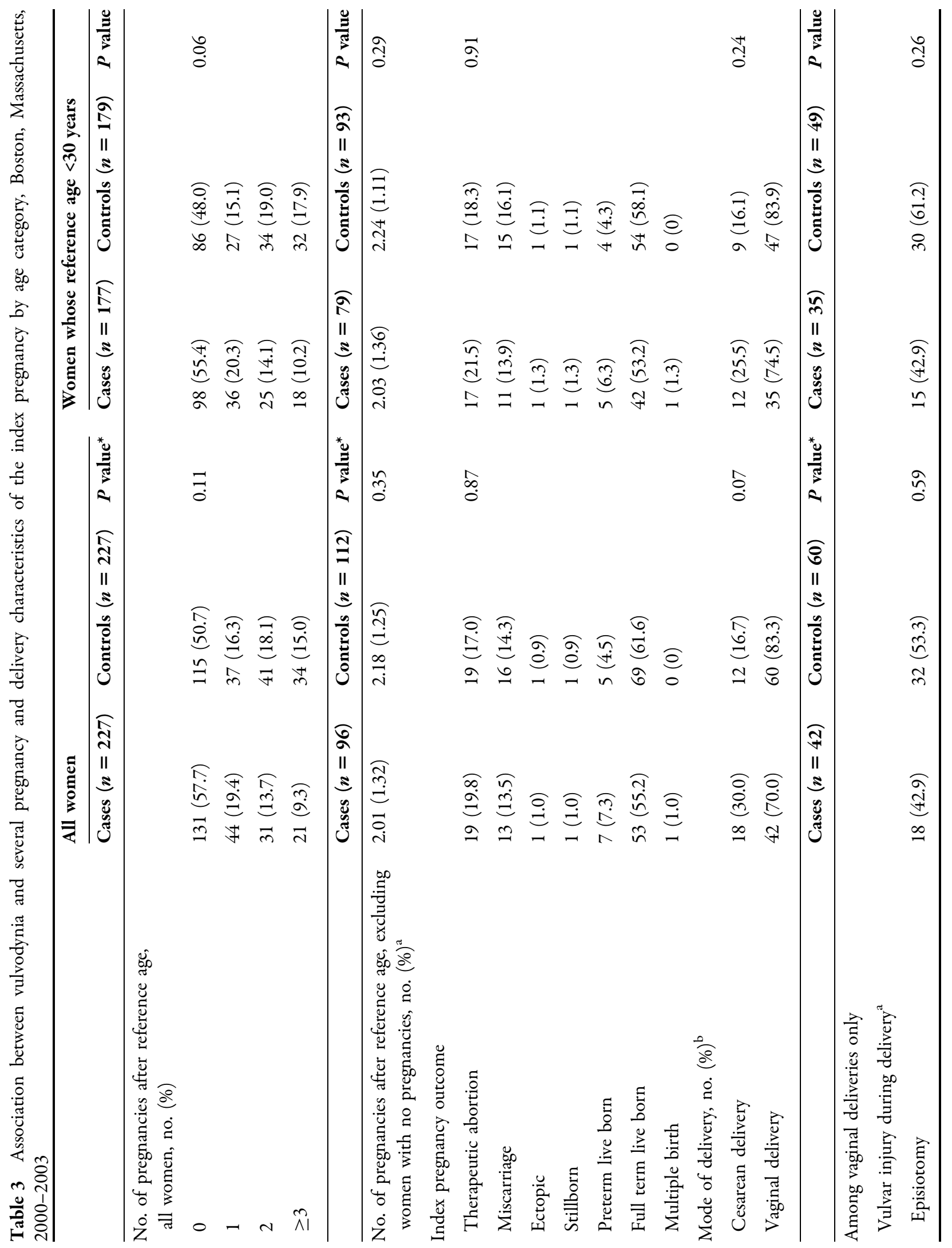




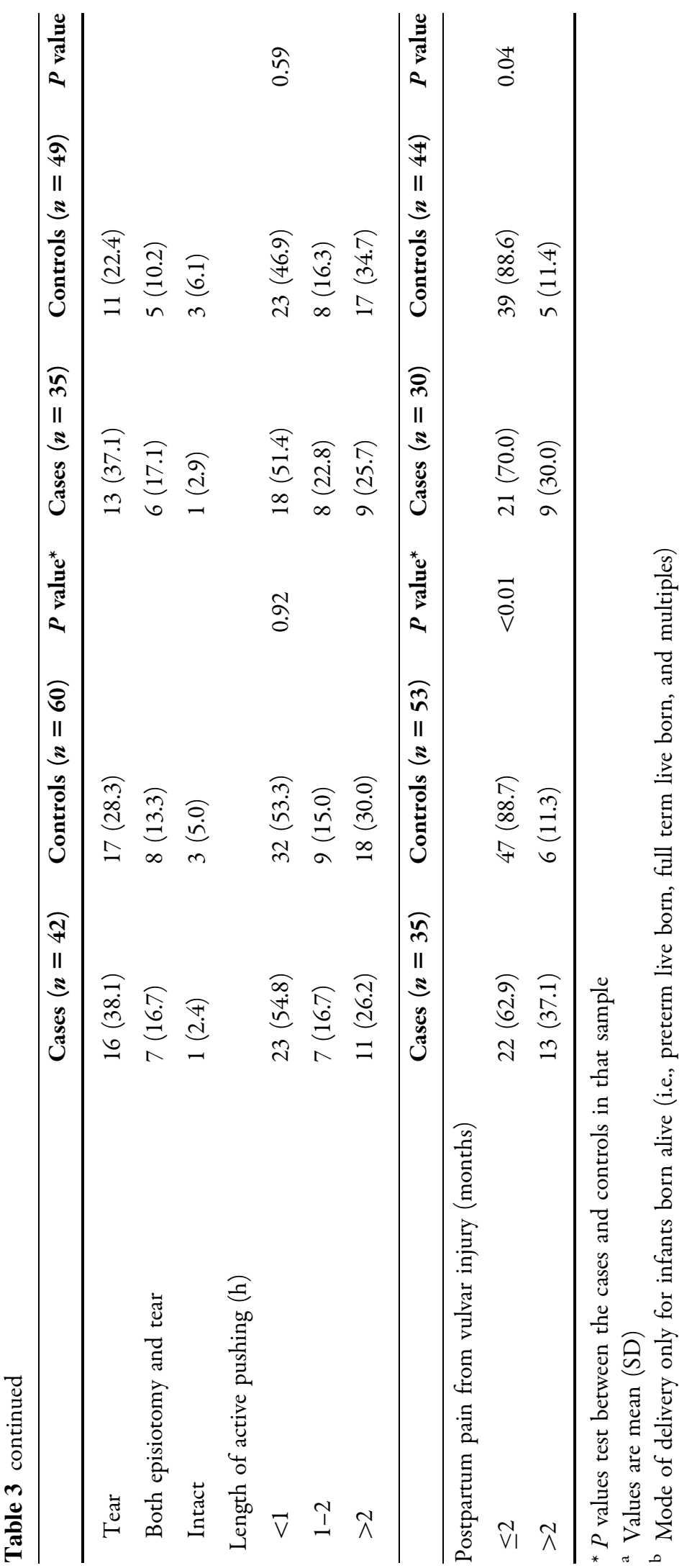


vulvar pain categories were restricted only to women who delivered vaginally (42 cases and 60 controls). The authors observed that receiving an episiotomy or tear was common (41 of 42 cases and 57 of 60 controls). Over one quarter of women pushed for more than $2 \mathrm{~h}$ during the delivery. However, the rate of experiencing vulvar pain associated with the vaginal delivery at over 2 months postpartum was higher among women with vulvodynia compared with those with no vulvar pain history $(37.1 \%$ vs. $11.3 \%, P<0.01$ for all women).

\section{Analysis of Determinants of Pregnancy Among Women with Vulvodynia}

Table 4 lists two multivariable logistic regression models, one for all women with vulvodynia and the other for women whose vulvar pain symptoms occurred before the age of 30 years. Among all women with vulvodynia, having vulvar pain that limited intercourse reduced the likelihood of pregnancy by $68 \%$ (adj. OR 0.32, 95\% CI 0.12-0.86), after accounting for other factors that may reduce a woman's likelihood of pregnancy, including pain consistency, race, and marital status (using stepwise regression, the final model excludes education). Among women who experience their first pain at less than 30 years, vulvar pain that limited intercourse reduced the odds of becoming pregnant by 69\% (adj. OR 0.31, 95\% CI 0.10-0.96), and intermittent versus constant vulvar pain increased the odds of pregnancy among these women (adj. OR $2.26,95 \%$ CI $1.10-4.60)$.

\section{DISCUSSION}

This is among the first descriptive studies of pregnancy outcome among women with vulvodynia. The authors' findings suggest no significant difference between women with and without vulvodynia with regards to having a pregnancy, or the outcomes for those pregnancies. These findings were consistent even among the subsample of cases (and matched controls) that developed chronic vulvar pain at a younger age. While the authors lacked complete information on the indication for the mode of delivery, cases were perhaps more likely than controls to receive a Cesarean section delivery. Finally, among those who delivered vaginally, women with vulvodynia were significantly more likely to experience postpartum pain at 2 months compared with control women. The present study is the first to explore pregnancy subsequent to the age of pain onset; thus, adding a level of temporality to the interpretation of the present results.

The present data could support the hypothesis that vulvodynia has no underlying biologic effect on a woman's fertility. Instead, a behavioral role could be hypothesized. The literature supports an effect of vulvodynia on the frequency of sexual intercourse, suggesting perhaps reduced fertility. Diminished libido and reduced sexual intercourse has been reported


However, natural conception is possible among women with vulvodynia, for example, if couples time their intercourse to occur around ovulation to reduce episodes of vulvar pain. However, this may not be possible for all women with vulvodynia. Indeed, women with vulvodynia in the present sample tended to be less likely to have a pregnancy after developing vulvodynia symptoms if their pain limited sexual intercourse or was constant versus remittent.

The authors were unable to determine pain levels during pregnancy. Consistency of pain 


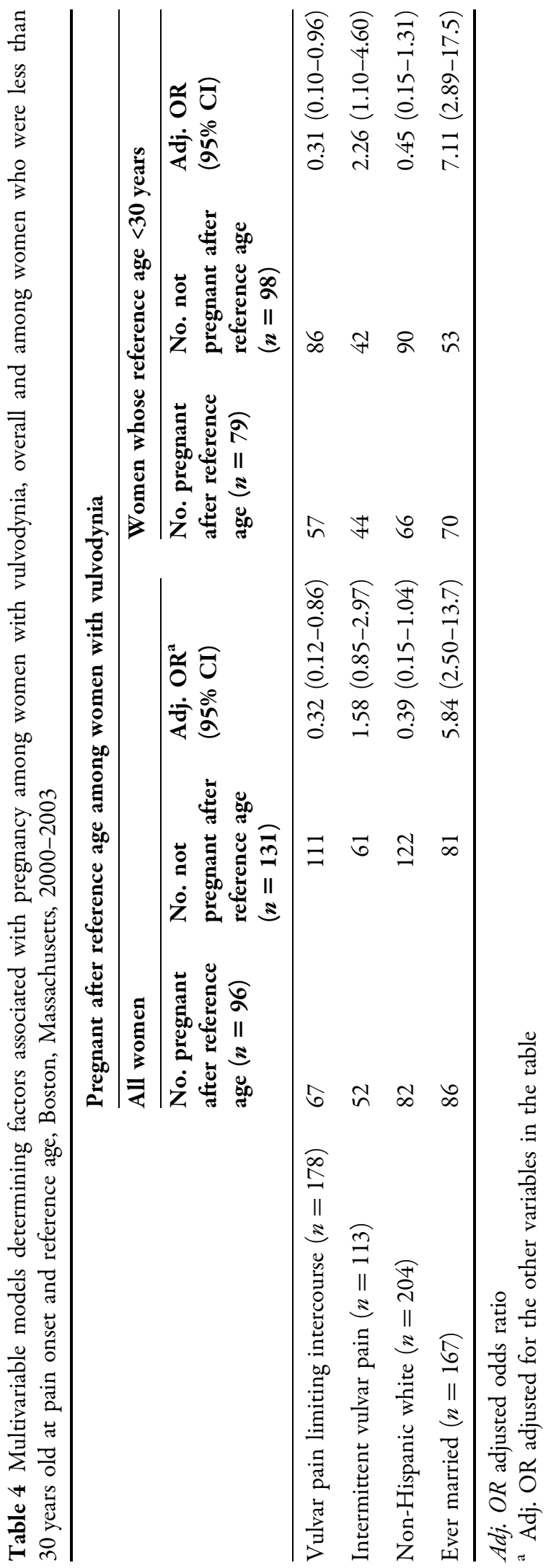


may change over a woman's lifetime, with the possibility of remission of vulvar pain symptoms naturally or as a result of efficacious treatment. Reed et al. [7] have reported that each year approximately $10 \%$ of women with a history of vulvodynia will experience remission of symptoms (defined as lack of symptoms at interview). However, it remains unclear what role, if any, medication use and efficacy plays in eliminating vulvodynia symptoms. Factors that were associated with remission were the lack of pain during intercourse and less severe pain. As these symptoms were similar to what the authors found for factors that were suggested to be associated with achieving pregnancy after the onset of vulvodynia (i.e., lack of pain during intercourse and remittent pain), it may be plausible that women with a history of vulvodynia may be in remission by the time they become pregnant and deliver.

It is common for women in the general population to experience pain with sex after delivery, particularly after vulvovaginal trauma during delivery [8]. However, the authors found that pregnant women with vulvodynia do experience greater risk of vulvar pain after vaginal delivery that included an episiotomy or tear compared with controls. Reed et al. [7] have reported that despite symptoms waning over time, few women with vulvodynia find that all symptoms vanish. The present data suggest that vaginal delivery may be one mechanism that triggers vulvar pain symptoms. The triggering of vulvar pain is a plausible theory because many women report pain with sex during the postpartum period [9]. In fact, a recent report found that women with persistent genital or pelvic pain were at increased risk of having pain for longer than 1 year after delivery [10].

Although the authors were initially interested in determining factors associated with the mode of delivery, especially because Cesarean section deliveries tended to be more common among women with vulvodynia in the present study, the authors only had 42 women with vulvodynia who delivered vaginally, and the power to determine statistical differences was low.

Important limitations of the present data include the authors' inability to define women's pain level throughout the pregnancy. The present finding that women with a history of vulvodynia who become pregnant may have greater pain during the postpartum period than controls may be directly related to pain during that pregnancy. Without those data, the authors are unable to differentiate heterogeneous risks among women with vulvodynia. Similarly, the authors lacked detailed information on individual pregnancies, including medications used to alleviate vulvar pain during or after pregnancy (including whether the woman was in remission during the pregnancy), the length of time vulvar pain persisted after delivery, indication for Cesarean delivery, or types of assisted reproductive therapies. These factors have the potential to mediate the present findings. However, there is no current evidence to suggest the direction of the possible impact.

Second, the present study was largely confined to vestibulodynia, or localizedprovoked vulvodynia. The factors affecting both pregnancy and pain after delivery may be specific to the woman's type of vulvar pain. However, these types may be one condition representing different stages of severity on the same pain continuum [11]. The present results should be interpreted with more confidence for women with localized-provoked vulvodynia because these were the majority of cases that were clinically confirmed.

Finally, the authors rely on women's recall of pregnancy and delivery characteristics. 
In general, maternal recall has been found to be reasonably accurate [12], but not without inaccuracies [13]. Previous studies have found that the major threat to validity of maternal recall for perinatal events depends on specific measures, such as infant characteristics and pregnancy complications. The authors are not aware of any previous study assessing the validity of vulvar pain after delivery. However, there has been excellent reliability and validity of reporting vulvar pain, and confirming vulvodynia [14].

\section{CONCLUSION}

In this sample of women the authors found no evidence that women with vulvodynia were less likely to achieve pregnancy than controls. However, those cases reporting intermittent vulvar pain appeared to be more likely than those with constant pain to become pregnant, while those with vulvar pain that limited intercourse were less likely than those with lesser pain to become pregnant. Once women with vulvodynia achieved pregnancy, there was little evidence to suggest that vulvodynia affected the pregnancy outcome (e.g., live births). In addition, women with vulvodynia who experienced an episiotomy or tear during vaginal delivery were more likely to experience vulvar pain 2 months postpartum compared with controls, but it is unclear whether this postpartum pain is mediated by a woman's level of pain during that pregnancy. Future studies of pregnancy and family planning among women with vulvodynia should include examination of limiting vulvar pain around conception. These may include measures of timing intercourse around ovulation or methods of intrauterine insemination procedures.

\section{ACKNOWLEDGMENTS}

The authors thank Allison Vitonis for her programming assistance. This research was supported by a grant from the National Institute of Child Health and Human Development (NIH-R01-HD38428). Results were presented as a poster presentation at the 42nd Annual Society for Epidemiologic Research meeting in Anaheim, California, 2009, and an oral presentation at the XXth World Congress of the International Society of the Study of Vulvovaginal Disorders. Dr. Nguyen is the guarantor for this article, and takes responsibility for the integrity of the work as a whole.

Conflict of interest. The authors report no conflict of interests with this publication.

Open Access. This article is distributed under the terms of the Creative Commons Attribution Noncommercial License which permits any noncommercial use, distribution, and reproduction in any medium, provided the original author(s) and the source are credited.

\section{REFERENCES}

1. Plante AF, Kamm MA. Life events in patients with vulvodynia. BJOG. 2008;115:509-14.

2. Reed BD, Advincula AP, Fonde KR, Gorenflo DW, Haefner HK. Sexual activities and attitudes of women with vulvar dysesthesia. Obstet Gynecol. 2003;102:325-31.

3. Reed BD, Haefner HK, Cantor L. Vulvar dysesthesia (vulvodynia). J Reprod Med. 2003;48:409-16.

4. Harlow BL, Stewart EG. Adult-onset vulvodynia in relation to childhood violence victimization. Am J Epidemiol. 2005;161:871-80. 
5. Bachmann GA, Rosen R, Pinn VW, et al. Vulvodynia: a state-of-the-art consensus on definitions, diagnosis and management. J Reprod Med. 2006;51:447-56.

6. Harlow BL, Vitonis AF, Stewart EG. Influence of oral contraceptive use on the risk of adult-onset vulvodynia. J Reprod Med. 2008;53:102-10.

7. Reed BD, Haefner HK, Sen A, Gorenflo DW. Vulvodynia incidence and remission rates among adult women: a 2-year follow-up study. Obstet Gynecol. 2008;112:231-7.

8. Barrett G, Pendry E, Peacock J, Victor C, Thakar R, Manyonda I. Women's sexual health after childbirth. BJOG. 2000;107:186-95.

9. Abdool Z, Thakar R, Sultan AH. Postpartum female sexual function. Eur J Obstet Gynecol Reprod Biol. 2009;145:133-7.

10. Paterson LQ, Davis SN, Khalife S, Amsel R, Binik YM. Persistent genital and pelvic pain after childbirth. J Sex Med. 2009;6:215-21.
11. Reed BD, Gorenflo DW, Haefner HK. Generalized vulvar dysesthesia vs. vestibulodynia. Are they distinct diagnoses? J Reprod Med. 2003;48:858-64.

12. Tomeo CA, Rich-Edwards JW, Michels KB, et al. Reproducibility and validity of maternal recall of pregnancy-related events. Epidemiology. 1999;10: 774-7.

13. Olson JE, Shu XO, Ross JA, Pendergrass T, Robison LL. Medical record validation of maternally reported birth characteristics and pregnancyrelated events: a report from the Children's Cancer Group. Am J Epidemiol. 1997;145:58-67.

14. Reed BD, Haefner HK, Harlow SD, Gorenflo DW, Sen A. Reliability and validity of self-reported symptoms for predicting vulvodynia. Obstet Gynecol. 2006;108:906-13. 